Bond University

Research Repository

\title{
Consumers' questions about antipsychotic medication: revealing safety concerns and the silent voices of young men
}

Weersink, Rianne A.; Taxis, Katja; McGuire, Treasure M.; van Driel, Mieke L.

Published in:

Social Psychiatry and Psychiatric Epidemiology

DOI:

10.1007/s00127-014-1005-y

Licence:

Other

Link to output in Bond University research repository.

Recommended citation(APA):

Weersink, R. A., Taxis, K., McGuire, T. M., \& van Driel, M. L. (2015). Consumers' questions about antipsychotic medication: revealing safety concerns and the silent voices of young men. Social Psychiatry and Psychiatric Epidemiology, 50(5), 725-733. https://doi.org/10.1007/s00127-014-1005-y

\section{General rights}

Copyright and moral rights for the publications made accessible in the public portal are retained by the authors and/or other copyright owners and it is a condition of accessing publications that users recognise and abide by the legal requirements associated with these rights.

For more information, or if you believe that this document breaches copyright, please contact the Bond University research repository coordinator 


\section{Title Page}

Title: Consumers' questions about antipsychotic medication: revealing safety concerns and the silent voices of young men

\section{Authors:}

- $\quad$ Rianne A. Weersink

- Department of Pharmacy, Unit of Pharmacotherapy and Pharmaceutical Care, University of Groningen, Antonius Deusinglaan 1, 9713 AV Groningen, The Netherlands

- Discipline of General Practice, School of Medicine, The University of Queensland, Level 8 Health Sciences Building, Herston QLD 4029, Brisbane, Australia

- $\quad$ Katja Taxis

- Department of Pharmacy, Unit of Pharmacotherapy and Pharmaceutical Care, University of Groningen, Antonius Deusinglaan 1, 9713 AV Groningen, The Netherlands

- Treasure M. McGuire

- Mater Pharmacy Services, Level 3, Mater Children's Hospital, Mater Health Services, South Brisbane, 4101, Australia

- School of Pharmacy, PACE Precinct, Building 870, The University of Queensland QLD 4072, Australia

○ Faculty of Health \& Medical Sciences, Bond University, Gold Coast, 4229, Australia

- Mieke L. van Driel

- Discipline of General Practice, School of Medicine, The University of Queensland, Level 8 Health Sciences Building, Herston QLD 4029, Brisbane, Australia, Phone: +61 7336 55144, Fax: +61 73346 5178, m.vandriel@uq.edu.au

\section{$\underline{\text { Word count }}$}

Abstract: 251 words

Text: 3,245 words 


\begin{abstract}
Purpose: Little is known about consumer information needs regarding antipsychotic medicines. Medicines call centre (MCC) derived data are underutilised; and could provide insight into issues of importance to consumers. This study aimed to explore consumers' information needs about antipsychotic medication sought from a national MCC in Australia.

Methods: Questions received by the National Prescribing Service (NPS) Medicines Line relating to antipsychotic medication from September 2002 to June 2010 were examined by antipsychotic subclass and in relation to other medication queries.

Results: We identified $\underline{6,295}$ calls related to antipsychotic medication. While female callers predominated, the percentage of males with antipsychotic questions was statistically significantly higher than for other medication calls $(33.9 \%$ vs $22.6 \% ; \mathrm{p}<0.001)$. There were distinct gender differences in medicines information seeking across age ranges. Younger men asked about secondgeneration antipsychotics, shifting towards first-generation antipsychotics after 45 years of age. Female interest in both subclasses was comparable, irrespective of age. Most callers asking about antipsychotics sought information for themselves (69.4\%). Callers were primarily concerned about safety $(57.0 \%)$, especially adverse drug reactions (28.8\%), and were more often prompted by a worrying symptom $(23.8 \%)$ compared with the rest of calls (17.2\%). Trends of antipsychotic questions received corresponded with antipsychotic prescription data.

Conclusions: The number of calls received by this MCC over time reveals an ongoing consumer need for additional, targeted information about antipsychotics. Noticeable was the relatively high frequency of young male callers asking about antipsychotics, indicating that call centres could be a way to reach these traditionally poor users of health services.
\end{abstract}

Keywords: antipsychotic agents, information seeking behaviour, consumer health information, medicines call centre, health information seeking, medicines information seeking 


\section{Introduction}

Mental illness constitutes a large and increasing burden of disease in Australia and worldwide [1]. Psychotic disorders, in particular schizophrenia that requires lifelong treatment, contribute significantly to health burden and costs [2]. Prescribing of antipsychotics has increased markedly in Europe, North America and Australia in recent years [3-5]. It is therefore not surprising that consumers' need for information about antipsychotics is also growing.

When looking for information about medicines, consumers use a diverse range of information sources such as their doctor, pharmacist, the internet or consumer medication information (CMI) leaflets [6-8]. Another valuable resource is a medicines call centre (MCC) [9-11]. Information provided with prescription medicines is often perceived as inadequate by consumers [12]; and a MCC can be helpful to fill the information gap. Although there is extensive literature covering the area of health information seeking behaviour [13-15]; studies about medicines information seeking are limited. There is, specifically, a lack of studies about consumers' antipsychotic medication information needs. Data derived from a MCC is an underutilised resource and could provide insight into antipsychotic-related issues of concern to consumers. The aim of this study was to profile antipsychotic medication information seekers and explore their information needs, as presented to a national MCC in Australia. 


\section{Methods}

\section{Study site}

Medicines Line is a national MCC, funded by the National Prescribing Service (NPS), to promote quality use of medicines by providing information that is independent, evidence-based and safe. Consumers could access the service for information about prescription, over-the-counter or complementary medicines for the cost of a local call, Monday to Friday 9am to 6pm, from anywhere in Australia, or leave a voicemail for a return call or to request consumer medicines information leaflets. Callers were also encouraged to discuss the information provided with their doctor or pharmacist. While marketing was primarily via the NPS website, the service was promoted in the media as part of National Medicines Week in 2007 and 2008. Between its launch in September 2002 and 30 June 2010, the service was operated by experienced clinical pharmacists at Mater Health Services, Brisbane.

Information collected during the call was recorded by the pharmacist on a standardised, scannable form, with the call narrative entered into a Microsoft Access $^{\mathrm{TM}}$ database, linked by the unique scanform number. Information included demographic data of the caller, the patient and the relationship between caller and patient. Details of questions were collected, such as enquiry type and motivation for calling.

Medicines involved in the call were recorded and categorised into major groups, based on the Anatomical Therapeutical Chemical (ATC) classification of the World Health Organization [16]. Major groups were further divided into minor therapeutic classes, based on the Monthly Index of Medical Specialties (MIMS) Australia classification [17]. MIMS is a source for medicine's product information, available for Australian healthcare professionals.

\section{Data extraction}


different and unique mechanism of action. Calls related to lithium have been included in the

\section{Analyses}

The MCC service Access ${ }^{\mathrm{TM}}$ database was exported to $\mathrm{SPSS}^{\circledR}$ version 21 for statistical analyses. Frequency tables were computed for caller demographics and question characteristics; these were compared by antipsychotic subclass. Data from antipsychotic-related calls were also compared with the rest of calls in the database. A chi-square test was used to compare dichotomous and categorical variables and an independent sample t-test was used to compare continuous variables. A p-value of $\leq 0.05$ was applied to indicate statistical significance.

In addition, for the primary medicine of interest, the temporal relationship between antipsychotic classes of interest to consumers in this cohort relative to the dispensing of antipsychotic prescriptions (actual medicine use) was explored. Comparisons were made between annual calls about antipsychotics (first- and second-generation antipsychotics) and national prescription data from the Australian Statistics on Medicines (ASM) which provides annual dispensed prescription totals for medicines, based on a combination of Pharmaceutical Benefits Scheme (PBS) data and community pharmacy data [20]. Percentages per antipsychotic subclass were calculated using the total number of Medicines Line calls and the sum of all dispensed item types for that class in ASM, for 2002 to 2010 inclusive, as denominators.

\section{Ethical Approval}


This study was undertaken as part of a program of research that has received 'Low and Negligible

1 Limited (HREC Protocol Ref No: LNR submission 2012-68). 


\section{Results}

A total of 125,919 calls were available for analysis concerning 195,855 medications. Antipsychotic-related calls accounted for $5.0 \%(n=6,295)$ of total calls. Of these calls, most $(89.1 \%)$ involved a question about a single antipsychotic while the remaining $10.9 \%$ included two or more antipsychotics. This equates to an average of 1.1 (mode 1; range 1-3) antipsychotic medications per enquiry.

Among the 6,295 calls involving at least one antipsychotic, an antipsychotic was the primary medicine in 4,398 calls. This primary medicine of interest was a second-generation antipsychotic in $81.0 \%(n=3,564)$ of these calls, most commonly olanzapine, quetiapine and risperidone. Of the 834 calls (19.0\%) where a first-generation antipsychotic was the primary medicine, the focus was on chlorpromazine, haloperidol and pericyazine.

In Figure 1, the calls received by Medicines Line for subgroups of antipsychotics (first- and second-generation) per year is compared to the sum of all prescriptions dispensed for these subgroups in Australia. This comparison shows a similar trend over time between the percentage of calls per antipsychotic subgroup (medicine of interest in this cohort) and the percentage of prescriptions dispensed per antipsychotic subgroup from 2002 to 2010 (national medication use) [20].

Besides antipsychotics, other medications frequently involved in antipsychotic-related questions were sodium valproate (5.6\% of antipsychotic calls), diazepam (4.6\%) and lithium (4.0\%) - all these agents act on the nervous system.

\section{Characteristics of callers}

Table 1 lists characteristics of callers to the service. While females were the predominant caller, the percentage of male callers with questions about antipsychotics (33.9\%) was significantly higher compared with the $22.6 \%$ of males calling for other medication $(p<0.001)$. The mean age of callers for antipsychotic-related queries was 46.0 years (SD 14.6; range 16-98). They were significantly younger $(p<0.001)$ than callers for the 'rest of calls' (mean age 50.8 years, SD 17.9; range 5-100). 
Approximately $70 \%$ of callers for both antipsychotic and other medication information rang on

\section{Reasons for calling}

Table 2 lists the motivation for calling the MCC. Across all calls, the major reasons were inadequate information, a worrying symptom or requiring a second opinion. Antipsychotic-related 
calls were more often prompted by a worrying symptom $(23.8 \% ; n=1,491)$ than the rest of calls $(17.2 \% ; n=20,442)(p<0.001)$. There was no difference in the information needs of people calling for themselves or for another person.

\section{Prior information source}

Callers ringing about antipsychotic medication $(n=6,295)$ cited 7,645 information sources used before contacting Medicines Line compared with the remaining 119,624 callers who nominated 143,271 sources. This suggests that consumers frequently use more than one source when seeking medicines information. In both cohorts, health professionals were important 'prior information sources', consulted in more than half of calls. The doctor was the main prior information source (40.6\% for antipsychotic-related calls $(n=2,557)$ and $33.2 \%$ for rest of calls $(n=39,681))$.

\section{Narrative of enquiries}

Medication safety was the main caller concern, accounting for almost $60 \%$ of calls $(n=3,578)$ about antipsychotics (Table 2). Noticeable from individual enquiry types was the high number of calls received about adverse drug reactions (ADRs), with a frequency of $28.8 \%$ ( $n=1,810)$ for antipsychotic-related calls versus $18.7 \%(n=22,280)$ for rest of calls $(p<0.001)$. The frequencies of other individual enquiry types were reasonably consistent compared to other medicines.

When call narrative was explored for key themes, safety-related questions focused on sideeffects, risks in special populations and interactions. Some examples:

- 'Are any of my medicines (sertraline, haloperidol) causing my drowsiness and bleeding nose?'

- 'Will I get addicted to Zyprexa (olanzapine)?'

- 'What should I do to treat the constipation caused by my chlorpromazine and quetiapine?'

- 'How long will my side effects of pain in the legs and sedation due to paliperidone last?'

Questions about the risks in special populations included 'Would I be able to breastfeed my new born baby if I have been on olanzapine throughout my pregnancy and will most likely continue on it after 
baby is born?'; while interaction questions often involved another psychiatric medication, complementary or lifestyle drug e.g. 'Can my son take Aurorix (moclobemide) if he is on Zyprexa (olanzapine)?' or 'Do my complementary medicines interact with olanzapine?' Safety concerns about antipsychotics were followed by a desire for information on medication effectiveness. For instance: 'How quickly will Neulactil (pericyazine) start to work?', or 'Would ziprasidone be a better drug than olanzapine with regards to weight gain and diabetes?' 


\section{Discussion}

Our study profiled antipsychotic medication information seekers and identified an apparent unmet need for information about antipsychotic medicines, particularly in young males.

\section{Characteristics of (antipsychotic) medication information seekers}

The profile of callers asking about medicines in general and antipsychotics in particular is predominantly female, seeking information for themselves or a significant other. This is consistent with the literature suggesting that women tend to seek health information more often than men $[13,14,23]$, and for either themselves or a 'family' member [24]. It also aligns with data from other MCCs $[25,26]$. However, our study found a relatively high proportion of (young) males calling Medicines Line for information about antipsychotics. The literature is less clear in relation to caller age. Some studies about health seeking behaviour suggest that younger individuals are more likely to health seek $[14,27,28]$ while others note a positive relationship with increasing age $[13,29]$. In our study, while callers seeking information on antipsychotics were spread across a wide age range supporting both paradigms, they were, on average, a younger cohort. This could be explained by the age of onset of psychosis, which is often in early adulthood [30]. This is also when affected individuals are having their first experiences of taking antipsychotic medications, potentially triggering information seeking behaviour.

Studies suggest that young males are less likely to help seek [13,29] or access health services [29], in particular for mental health disorders $[29,31,32]$. However, it is unlikely that they have fewer questions than, for instance, young women. Perhaps they are not getting the answers they need through conventional channels? It is possible that young men feel more comfortable contacting a call centre instead of directly facing a healthcare professional. This is in line with mental health patients' preference for anonymous sources for health and medicines information [33-35]. Consultation via a telephone service could therefore be a way for them to voice questions about 
their health and for health services to reach this group of consumers. Further research is needed to confirm and explore this finding.

\section{MCCs as a source for (antipsychotic) medication information}

In a country as vast as Australia, there are challenges of providing equitable access to quality health services in rural and remote areas. A medicines information service with direct phone access to a pharmacist has the potential to overcome the tyranny of distance and meet the needs of rural as well as urban consumers, independent of location. However, this does not always equate to actual service utilisation. In this study, calls relating to antipsychotics not only originated from all Australian states and territories, but also importantly, people calling from 'remote' areas approached the relative population frequency. This supports that the MCC service model had utility for mental health consumers in rural and remote areas where there is likely to be less access to mental health services.

Although the two variables in Figure 1 use different denominators, over an eight year period, there was a close parallel between the percentage of calls about antipsychotic subgroups (medicine of interest in this cohort) and the percentage of antipsychotic prescriptions dispensed annually (national medicine use). This longitudinal perspective, together with the quantum of calls received over time, reveals the ongoing need consumers have for quality information about (all subgroups of) antipsychotic medication. This need was also recognized in other MCC studies $[25,26]$.

\section{Link between uncertainty and motivation to seek medicines information}

Uncertainty, related to an information gap or a symptom of concern, has been shown to drive health seeking behaviours such as seeking medicines information $[13,14,36,37]$. Inadequate information was the main reason for contacting this $\mathrm{MCC}$, in both antipsychotic-related and the remainder of calls. Consumers receiving inadequate information tend to be dissatisfied with the 
information available to them and want to know more, supporting the existence of a knowledge gap for almost half of those seeking information on antipsychotics [38-40].

The second main motivation for calling the MCC with antipsychotic medication questions was a 'worrying symptom'. The higher number of questions prompted by a worrying symptom in relation to antipsychotics compared with 'rest of calls' is supported by the frequent occurrence of adverse effects with antipsychotics [41]. In almost half of total antipsychotic-related calls, the prior information source previously consulted was not a health care professional but, for instance, the internet. It is of concern that this cohort had not sought help from their health carers about this worrying symptom prior to contacting the service. The call, however, provided an opportunity for a MCC pharmacist to decrease caller uncertainty about their medication-related issue, and appropriately triage callers requiring review by their doctor. Another important prompt in both types of calls was 'second opinion'. Studies that assessed the motivation of people to seek health information on the internet also highlighted 'second opinion' as a prompt for health seeking behaviour - the hope to find something 'new' $[42,43]$. Since there is limited literature available about motivation for health seeking behaviour, these findings could provide a foundation for further research.

\section{Narrative of medicine information seeking}

Safety was the main concern of callers with those asking for information about antipsychotics more frequently wanting information about adverse drug reactions than callers for other medication. Safety as a goal of medicines information seeking is in agreement with literature about medicines information needs of consumers $[8,44]$ and with findings from other MCCs $[9,26,45]$. Medicines information provided by healthcare professionals or accompanying medication, such as the Consumer Medicines Information (CMI) leaflet, should therefore focus more on safety issues, in particular strategies to minimise or monitor risk. Antipsychotics are medications with a high sideeffect burden [41], which can be worrying and trigger health seeking behaviour. Qualitative studies 
involving mental health patients revealed a knowledge gap among patients, especially about adverse

\section{Limitations}

The Medicines Line service model was developed as a cost-effective strategy to meet the medicines information needs of Australian consumers; it was not created as a data repository for research. As a result, there are missing data, especially in relation to the voicemail requests for $\mathrm{CMI}$ leaflets. The percentage of missing data is however not more than $5 \%$ for every characteristic and is reasonably comparable for both antipsychotic-related calls and rest of calls.

An addition, callers to a MCC are only part of the total group of medicine users. We do not know if the non-health information seeking consumer wants more or different information about their medicines. However, our study includes a significant proportion of questions from young males (often direct users of the antipsychotic medicines), who are known to be infrequent users of health services.

\section{Conclusion}

The number of calls received by this MCC reveals an ongoing need for additional information on antipsychotics from consumers. Noticeable was the relatively high frequency of young males contacting the MCC for safety information about antipsychotic medication, a cohort known to be poor users of health services. Acknowledging their preference for telephone consultation can help reach this group. Overall, MCCs are a valuable and underutilised repository for research on consumer medicines information seeking behaviour. 


\section{Acknowledgements}

We would like to acknowledge NPS MedicineWise (formerly National Prescribing Service,

Australia), funder of NPS Medicines Line and service provider since July 2010. We would also like to thank Mater Health Services for providing the raw service data from September 2002 to 30 June 2010; and Gabrielle Hartley, Mater Pharmacy Services, for database assistance.

This study was supported by a travel scholarship for Rianne Weersink from the Chiel Hekster Fund and the Stipendium Fund of the Koninklijke Nederlandse Maatschappij ter bevordering der Pharmacie (KNMP), The Netherlands.

\section{Conflict of Interest}

The sponsors had no role in study design; in the collection, analysis and interpretation of data; in the writing of the report; and in the decision to submit the paper for publication. On behalf of all authors, the corresponding author states that there is no conflict of interest. 


\section{References}

1. World Health Organisation (2001) The World Health Report 2001: Mental Health - New

Understanding, New Hope. World Health Organisation, Geneva

2. Rössler W, Joachim Salize H, van Os J, Riecher-Rössler A (2005) Size of burden of schizophrenia and psychotic disorders. Eur Neuropsychopharmacol 15 (4):399-409

3. Mental health services in Australia (2012) Mental-health related prescriptions. Australian Institute of Health and Welfare. http://mhsa.aihw.gov.au/resources/prescriptions/. Accessed 8 December 2012

4. Data and Modelling Section Pharmaceutical Policy and Analysis Branch (2011) Expenditure and prescriptions twelve months to 30 June 2011. Pharmaceutical Benefit Scheme.

http://www.pbs.gov.au/info/statistics/expenditure-and-prescriptions-30-06-2011. Accessed 21 January 2013

5. Verdoux H, Tournier M, Begaud B (2010) Antipsychotic prescribing trends: a review of pharmacoepidemiological studies. Acta Psychiatr Scand 121 (1):4-10. doi: 10.1111/j.1600-0447.2009.01425.x 6. Tio J, LaCaze A, Cottrell WN (2007) Ascertaining consumer perspectives of medication information sources using a modified repertory grid technique. Pharm World Sci 29 (2):73-80

7. Närhi U (2007) Sources of medicine information and their reliability evaluated by medicine users. Pharm World Sci 29 (6):688-694

8. Ho CH, Ko Y, Tan ML (2009) Patient needs and sources of drug information in Singapore: is the Internet replacing former sources? Ann Pharmacother 43 (4):732-739. doi: 10.1345/aph.1L580 9. Melnyk P, Shevchuk Y, Remillard A (2000) Impact of the dial access drug information service on patient outcome. Ann Pharmacother 34 (5):585-592

10. Bertsche T, Hammerlein A, Schulz M (2007) German national drug information service: user satisfaction and potential positive patient outcomes. Pharm World Sci 29 (3):167-172 
11. Marvin V, Park C, Vaughan L, Valentine J (2011) Phone calls to a hospital medicines information helpline: analysis of queries from members of the public and assessment of potential for harm from their medicines. Int J Pharm Pract 19 (2):115-122. doi: 10.1111/j.2042-7174.2010.00081.x 12. Svarstad BL, Mount JK, Tabak ER (2005) Expert and consumer evaluation of patient medication leaflets provided in US pharmacies. J Am Pharm Assoc 45:443-451

13. Dutta-Bergman MJ (2003) Developing a profile of consumer intention to seek our health information beyond a doctor. Health Mark Q 21 (1-2):91-112

14. Lambert SD, Loiselle CG (2007) Health information-seeking behavior. Qual Health Res 17(8):10061019

15. Anker AE, Reinhart AM, Feeley TH (2011) Health information seeking: A review of measures and methods. Patient Educ Couns 82 (3):346-354. doi: http://dx.doi.org/10.1016/j.pec.2010.12.008 16. World Health Organization Collaborating Centre for Drug Statistics Methodology (2010) Guidelines for ATC classification and DDD assignment, 2011. World Health Organisation, Oslo17. UBM Medica (2012) MIMS. MIMS Australia. http://www.mims.com.au/index.php/aboutmims/mims-australia. Accessed 27 September 2012

18. ABS (2009) National Health Survey: Summary of Results, 2007-2008. Australian Bureau of Statistics. http://www.abs.gov.au/AUSSTATS/abs@.nsf/mf/4364.0 Accessed 21 January 2013 19. Information and Research Branch Department of Health and Aged Care (2001) Measuring Remoteness: Accessibility/Remoteness Index of Australia (ARIA) New Series, vol Number 14. Department of Health and Ageing, Canberra 20. Australian Government Department of Health and Ageing (2004-2012) Australian statistics on medicines 2002-2010. Department of Health and Ageing. http://www.pbs.gov.au/info/browse/statistics. Accessed 4 February 2013 21. ABS (2012) Year Book Australia 2012; population and growth 2010. Australian Bureau of Statistics. http://www.abs.gov.au/ausstats/abs@.nsf/mf/1301.0. Accessed 11 February 2013 
22. ABS (2007) Australian Standard Geographical Classification (ASGC) Remoteness Structure (RA)

Digital Boundaries, Australia, 2006. Australian Bureau of Statistics, Canberra

23. Smith JA, Braunack-Mayer A, Wittert G (2006) What do we know about men's help-seeking and health service use? Med J Aust 184 (2):81-83

24. Warner D, Procaccino JD (2004) Toward wellness: Women seeking health information. J Am Soc Inform Sci Technol 55 (8):709-730

25. Pohjanoksa-Mantyla MK, Antila J, Eerikainen S, Enakoski M, Hannuksela O, Pietila K, Airaksinen M (2008) Utilization of a community pharmacy-operated national drug information call center in Finland. Res Social Adm Pharm 4 (2):144-152. doi: 10.1016/j.sapharm.2007.05.001

26. Huber M, Kullak-Ublick GA, Kirch W (2009) Drug information for patients-an update of longterm results: type of enquiries and patient characteristics. Pharmacoepidemiol Drug Saf 18 (2):111119. doi: $10.1002 / p d s .1682$

27. Gourash N (1978) Help-seeking: a review of the literature. Am J Community Psychol 6 (5):413423

28. Ramanadhan S, Viswanath K (2006) Health and the information nonseeker: a profile. Health Commun $20(2): 131-139$

29. Mackenzie CS, Gekoski WL, Knox VJ (2006) Age, gender, and the underutilization of mental health services: the influence of help-seeking attitudes. Aging Ment Health 10 (6):574-582 30. Kessler RC, Amminger GP, Aguilar-Gaxiola S, Alonso J, Lee S, Ustun TB (2007) Age of onset of mental disorders: a review of recent literature. Curr Opin Psychiatry 20 (4):359-64

31. Galdas PM, Cheater F, Marshall P (2005) Men and health help-seeking behaviour: literature review. J Adv Nurs 49 (6):616-623

32. Biddle L, Gunnell D, Sharp D, Donovan JL (2004) Factors influencing help seeking in mentally distressed young adults: a cross-sectional survey. Br J Gen Pract 54 (501):248-253

33. Pohjanoksa-Mäntylä M, Bell JS, Helakorpi S, Närhi U, Pelkonen A, Airaksinen M (2011) Is the Internet replacing health professionals? A population survey on sources of medicines information 
among people with mental disorders. Soc Psychiatry Psychiatr Epidemiol 46 (5):373-379. doi:

$10.1007 / \mathrm{s} 00127-010-0201-7$

34. Powell J, Clarke A (2006) Internet information-seeking in mental health. Br J Psychiatry 189

(3):273-277

35. Khazaal Y, Chatton A, Cochand S, Hoch A, Khankarli MB, Khan R, Zullino DF (2008) Internet use by patients with psychiatric disorders in search for general and medical informations. Psychiatr Q 79 (4):301-309. doi: 10.1007/s11126-008-9083-1

36. McGuire TM (2005) Consumer medicines call centres: a medication liaison model of pharmaceutical care. Dissertation, University of Queensland

37. Rosen NO, Knäuper B (2009) A little uncertainty goes a long way: State and trait differences in uncertainty interact to increase information seeking but also increase worry. Health Commun 24

(3):228-238. doi: $10.1080 / 10410230902804125$

38. Happell B, Manias E, Roper C (2004) Wanting to be heard: mental health consumers' experiences of information about medication. Int J Ment Health Nurs 13 (4):242-248

39. Powell J, Clarke A (2006) Information in mental health: qualitative study of mental health service users. Health Expect 9 (4):359-365

40. Gray R, Rofail D, Allen J, Newey T (2005) A survey of patient satisfaction with and subjective experiences of treatment with antipsychotic medication. J Adv Nurs 52 (1):31-37

41. Weiden PJ, Buckley PF (2007) Reducing the burden of side effects during long-term antipsychotic therapy: the role of "switching" medications. J Clin Psychiatry 68 (6):14-23

42. Eysenbach G, Diepgen TL (1999) Patients looking for information on the internet and seeking teleadvice: Motivation, expectations, and misconceptions as expressed in e-mails sent to physicians. Arch Dermatol 135 (2):151-156

43. Umefjord G, Petersson G, Hamberg K (2003) Reasons for consulting a doctor on the Internet: Web survey of users of an Ask the Doctor service. J Med Internet Res 5 (4):e26 
44. Newby DA, Hill SR, Barker BJ, Drew AK, Henry DA (2001) Drug information for consumers: should

it be disease or medication specific? Results of a community survey. Aust N Z J Public Health 25

(6):564-570

45. Grymonpre R, Steele J (1998) The medication information line for the elderly: an 8-year cumulative analysis. Ann Pharmacother 32 (7):743-748

46. Fleischhacker WW, Meise U, Günther V, Kurz M (1994) Compliance with antipsychotic drug treatment: influence of side effects. Acta Psychiatr Scand 89:11-15

47. Vermeire E, Hearnshaw H, Van Royen P, Denekens J (2001) Patient adherence to treatment: three decades of research. A comprehensive review. J Clin Pharm Ther 26 (5):331-342 


\section{Figures (created in Microsoft Excel)}

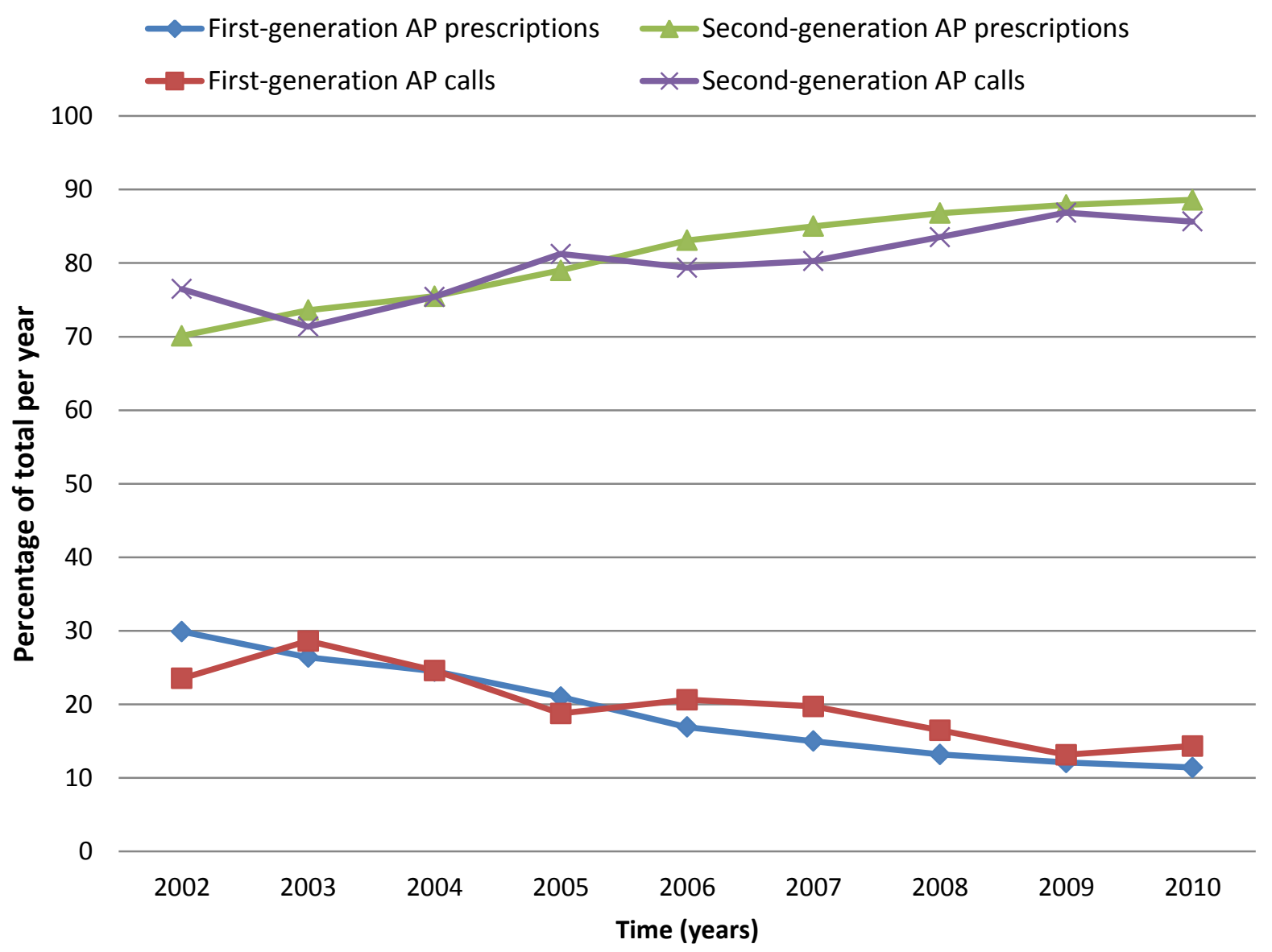

Fig. 1 Comparison of the distribution of subgroups of antipsychotics (first-generation and second-generation) per year for calls received by Medicines Line and the sum of all prescriptions dispensed for these subgroups in Australia. Percentages of calls were calculated using the total number of calls per year where an antipsychotic was the primary drug. For prescription data, percentages were calculated using the annual total of defined daily dose (DDD) per 1000 population per day per the Australian Statistics on Medicines [20]. $\mathrm{AP}=$ antipsychotic 


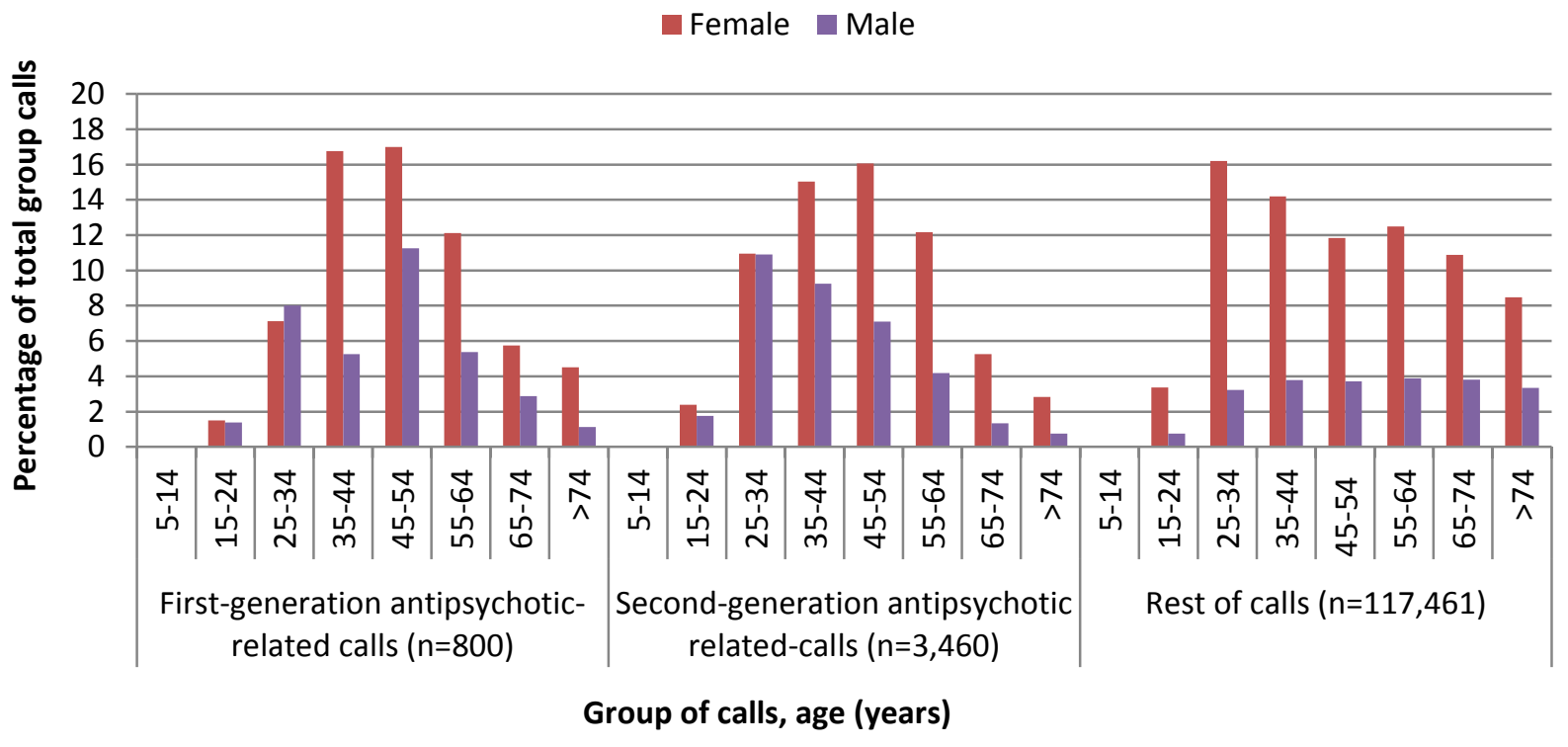

Fig. 2 Caller gender and age range compared for calls about first-generation antipsychotics, second-generation antipsychotics and rest of calls.

${ }^{\text {a }}$ Missing data for gender and/or age is omitted from these total number of calls: $n=34$ (4.1\% of 834 ) in firstgeneration antipsychotic-related calls, $n=104(2.9 \%$ of 3,564$)$ in second-generation antipsychotic-related calls and $n=2,163(1,8 \%$ of 119,624$)$ for rest of calls. 
$\underline{\text { Tables }}$

Table 1 Comparison of caller characteristics of antipsychotic-related and rest of calls

\begin{tabular}{|c|c|c|c|c|c|c|}
\hline & & \multicolumn{2}{|c|}{$\begin{array}{l}\text { Antipsychotic-related calls } \\
\qquad n=6,295\end{array}$} & \multicolumn{2}{|c|}{$\begin{array}{l}\text { Rest of calls } \\
n=119,624\end{array}$} & \multirow[t]{2}{*}{ Statistics } \\
\hline & & $\%$ & $n$ & $\%$ & $n$ & \\
\hline \multirow{2}{*}{ Gender (\%) } & Female & 66.1 & 4,159 & 77.4 & 92,452 & \multirow{3}{*}{$\begin{array}{c}\chi^{2}=430.6 \\
d f=1 \\
p<0.001\end{array}$} \\
\hline & Male & 33.9 & 2,136 & 22.6 & 27,009 & \\
\hline \multicolumn{2}{|c|}{ Total (missing omitted) ${ }^{\mathrm{a}}$} & 100.0 & 6,295 & 100.0 & 119,461 & \\
\hline \multicolumn{2}{|l|}{ Missing $^{b}$} & 0 & 0 & 0.1 & 163 & \\
\hline \multirow{9}{*}{ Age (years) } & $<5$ & 0 & 0 & 0 & 0 & \\
\hline & $5-14$ & 0 & 0 & 0 & 27 & \\
\hline & $15-24$ & 4.2 & 257 & 4.1 & 4,834 & \\
\hline & $25-34$ & 20.4 & 1,252 & 19.4 & 22,835 & \\
\hline & $35-44$ & 23.9 & 1,465 & 18.0 & 21,127 & \\
\hline & $45-54$ & 24.1 & 1,477 & 15.5 & 18,262 & \\
\hline & $55-64$ & 16.6 & 1,016 & 16.4 & 19,255 & \\
\hline & $65-74$ & 6.8 & 418 & 14.7 & 17,252 & \\
\hline & $\geq 75$ & 4.1 & 252 & 11.8 & 13,891 & \\
\hline \multicolumn{2}{|c|}{ Total (missing omitted) ${ }^{\mathrm{a}}$} & 100.0 & 6,137 & 100.0 & 117,483 & \\
\hline \multicolumn{2}{|l|}{ Missing $^{b}$} & 2.5 & 158 & 1.8 & 2,141 & \\
\hline \multicolumn{2}{|c|}{ Mean age (SD) } & \multicolumn{2}{|c|}{$46.0(14.6)$} & \multicolumn{2}{|c|}{50.8 (17.9) } & $\begin{array}{c}T=887.4 \\
\mathrm{df}=123,618 \\
p<0.001\end{array}$ \\
\hline \multicolumn{2}{|c|}{ Relationship (\% self) } & 69.4 & $4,3,365 / 6,286$ & 72.0 & $85,917 / 119,282$ & \multirow{2}{*}{$\begin{array}{c}\chi^{2}=19.8 \\
d f=1 \\
p<0.001\end{array}$} \\
\hline \multicolumn{2}{|l|}{ Missing } & 0.1 & 9 & 0.3 & 342 & \\
\hline
\end{tabular}

${ }^{a}$ Percentages are total of data available per variable. These may not add exactly to 100.0 due to rounding.

${ }^{b}$ Number and percentage of missing data per variable for total antipsychotic-related and rest of calls. Total missing data in rest of calls for gender and/or age $=2163$ with data about both gender and age missing for 141 callers. 
Table 2 Comparison of the motivation for contacting the MCC and the enquiry type, classified by relationship of the caller to the patient

\begin{tabular}{|c|c|c|c|c|c|c|c|c|}
\hline & \multicolumn{4}{|c|}{$\begin{array}{l}\text { Antipsychotic-related calls } \\
\qquad n=6,295\end{array}$} & \multicolumn{4}{|c|}{$\begin{array}{c}\text { Rest of calls } \\
n=119,624\end{array}$} \\
\hline & \multicolumn{2}{|c|}{ Self } & \multicolumn{2}{|c|}{ Other } & \multicolumn{2}{|c|}{ Self } & \multicolumn{2}{|c|}{ Other } \\
\hline & $\%$ & $n$ & $\%$ & $n$ & $\%$ & $n$ & $\%$ & $n$ \\
\hline \multicolumn{9}{|l|}{ Prompt } \\
\hline Inadequate information & 40.1 & 1,746 & 46.4 & 890 & 44.8 & 38,421 & 50.9 & 16,956 \\
\hline Worrying symptom & 24.3 & 1,058 & 22.6 & 433 & 18.3 & 15,663 & 14.3 & 4,779 \\
\hline Second opinion & 22.4 & 975 & 22.3 & 427 & 23.0 & 19,720 & 23.7 & 7,904 \\
\hline Conflicting information & 3.9 & 169 & 4.5 & 87 & 5.4 & 4,600 & 6.1 & 2,040 \\
\hline Other & 3.8 & 166 & 0.5 & 10 & 3.0 & 2,595 & 0.6 & 199 \\
\hline Information overload & 1.9 & 82 & 1.1 & 22 & 1.3 & 1,122 & 1.0 & 335 \\
\hline Forgot information & 1.6 & 68 & 0.8 & 15 & 1.5 & 1,301 & 1.0 & 346 \\
\hline $\begin{array}{l}\text { Professional } \\
\text { information source }\end{array}$ & 1.1 & 47 & 0.8 & 15 & 1.2 & 995 & 1.0 & 327 \\
\hline $\begin{array}{l}\text { Consumer information } \\
\text { source }\end{array}$ & 1.1 & 46 & 1.0 & 19 & 1.6 & 1,405 & 1.3 & 439 \\
\hline Total (missing omitted) ${ }^{\mathrm{a}}$ & 100.0 & 4,357 & 100.0 & 1,918 & 100.0 & 85,822 & 100.0 & 33,325 \\
\hline Missing $^{b}$ & \multicolumn{4}{|c|}{$0.3 \%(n=20)$} & \multicolumn{4}{|c|}{$0.4 \%(n=477)$} \\
\hline \multicolumn{9}{|l|}{ Enquiry Type } \\
\hline Safety & 58.5 & 2,551 & 53.5 & 1,027 & 53.6 & 46,003 & 54.6 & 18,206 \\
\hline Efficacy & 35.9 & 1,564 & 36.7 & 705 & 33.6 & 28,787 & 32.4 & 10,791 \\
\hline Judicious use & 4.4 & 191 & 9.2 & 177 & 7.9 & 6,756 & 9.9 & 3,289 \\
\hline Other & 1.2 & 52 & 0.6 & 11 & 4.9 & 4,214 & 3.1 & 1,049 \\
\hline Total (missing omitted) $^{\mathrm{a}}$ & 100,0 & 4,358 & 100.0 & 1,920 & 100.0 & 85,760 & 100.0 & 33,335 \\
\hline Missing $^{b}$ & \multicolumn{4}{|c|}{$0.3 \%(n=17)$} & \multicolumn{4}{|c|}{$0.4 \%(n=529)$} \\
\hline
\end{tabular}

${ }^{a}$ Percentages are total of data available per variable. These may not add exactly to 100.0 due to rounding.

${ }^{b}$ Number and percentage of calls where the relationship of the caller to the patient (self/other) and/or the prompt/enquiry type of the call is missing. 